\title{
ANALISIS KEBUTUHAN SUMBER DAYA MANUSIA DAN KUALITAS PELAYANAN FARMASI DI RS AMIRA PURWAKARTA
}

\author{
Agan Syahrial, Shirly Kumala, Prih Sarnianto, Yetti Hersunaryati \\ Fakultas Farmasi Universitas Pancasila Jakarta, Indonesia \\ Email: agansyahrial88@gmail.com,fskumala@yahoo.com, prih1488@gmail.com, \\ yetti_hersunaryati@yahoo.com
}

\begin{abstract}
Abstrak
Program Jaminan Kesehatan Nasional (JKN) yang diselenggarakan sejak 2014 telah membuat jumlah pasien di rumah sakit, termasuk RS Amira Purwakarta, meningkat tinggi. Peningkatan akan berlanjut seiring pencapaian cakupan semesta JKN pada 2019 ini harus diantisipasi dengan perencanaan pemenuhan sumber daya manusia (SDM) yang memadai guna memastikan tercapainya kualitas pelayanan kesehatan minimum. Untuk menghitung jumlah keperluan SDM dilakukan dengan metode WISN (Work Load Indikator Staff Need) dan analisis kualitas pelayanan farmasi menggunakan metode wawancara dan survei. Hasil penelitian menunjukkan masih kurangnya personel, yaitu 1 tenaga administrasi dan 3 tenaga teknis kefarmasian (TTK) dan penambahan kebutuhan SDM diharapkan akan memperbaiki kualitas pelayanan kefarmasian. Menurut kepala IFRS dapat dilakukan dengan pelatihan teknis kepada karyawan, pembenahan dan penambahan fasilitas fisik, perluasan area instalasi farmasi dan sistem distribusi terdesentralisasi, dan Evaluasi SOP, serta Evaluasi Penerapan Formularium.
\end{abstract}

Kata Kunci: jumlah SDM; WISN; beban kerja; kepuasan; kualitas pelayanan

\section{Abstract}

Number of patient in most of hospitals, including Amira Purwakarta, has been greatly been rising since 2014, When the National Health Insurance (Jaminan Kesehatan Nasional $(J K N))$ was initialized. JKN steady rise that is in the with the universal health coverage in 2019 should be anticipated by a good human resources planing and management to ensure the hospital would achieved minimum health quality. This study used WISN (Workload Indicator of Staffing Need) to figure out the number of staffs needed along with interviews and surveys to analize service quality. The result showed that there is a small shortage of personnel, i.e, 1 administration staff and 3 tenaga teknis kefarmasian (TTK), and the fulfillment of the human resource gap is exspected to be able to improve service quality in pharmacy. According to the interview with the Head of Pharmacy, it can be done by conducting technical training for staffs, improvement and procurement of tangible facilities, area extension of pharmacy installation, desentralized distribution system, SOP evaluation and evaluation of the National Formularies implementation.

Keywords: human resource; WISN; workload; satisfaction; service quality

$\begin{array}{ll}\text { How to cite: } & \text { Syahrial. A., Shirly Kumala, Prih Sarnianto \& Yetty Hersunaryati (2022) Analisis Kebutuhan Sumber Daya } \\ & \text { Manusia dan Kualitas Pelayanan Farmasi Di RS Amira Purwakarta. Syntax Literate: Jurnal Ilmiah Indonesia, } \\ & 7(1) . \text { http://dx.doi.org/10.36418/ Syntax-Literate.v7i1.6004 } \\ \text { E-ISSN: } & \text { 2548-1398 } \\ \text { Published by: } & \text { Ridwan Institute }\end{array}$


Agan syahrial, Shirly Kumala, Prih Sarnianto, Yetty Hersunaryati

Received: 2021-12-20; Accepted: 2022-01-05; Published: 2022-01-15

\section{Pendahuluan}

Sumber daya manusia (SDM) dapat didefinisikan sebagai keseluruhan penentuan dan pelaksanaan berbagai aktifitas, kebijakan, dan program yang bertujuan mendapatkan tenaga kerja, pengembangan, dan pemeliharaan dalam usaha meningkatkan dukungannya terhadap peningkatan efektivitas organisasi dengan cara yang secara etis dan sosial dapat dipertanggungjawabkan. SDM juga harus dicari yang andal, SDM yang andal hanya dapat diperoleh dengan perencanan SDM yang akurat, artinya SDM yang sesuai dengan kebutuhan dan memiliki kompetensi yang sesuai dengan bidang pekerjaannya (Sembiring \& SH, 2010).

Sesuai dengan Permenkes tentang Standar Pelayanan Kefarmasian Tahun 2016, pelayanan kefarmasian di rumah sakit merupakan bagian yang tidak terpisahkan dari sistem pelayanan kesehatan rumah sakit yang berorientasi kepada pelayanan pasien, penyediaan sediaan farmasi, alat kesehatan, dan bahan medis habis pakai yang bermutu dan terjangkau bagi semua lapisan masyarakat termasuk pelayanan farmasi klinik (Peraturan Menteri Kesehatan Republik Indonesia, 2016).

Instalasi farmasi pada rumah sakit (IFRS) harus memiliki apoteker dan salah satu persyaratan dalam SDM adalah tenaga teknis kefarmasian (TTK) yang sesuai dengan beban kerja serta petugas penunjang lain. Agar tercapai sasaran dan tujuan IFRS. Ketersediaan jumlah tenaga apoteker dan TTK di rumah sakit harus dipenuhi. Sesuai dengan ketentuan klasifikasi dan perizinan rumah sakit yang ditetapkan oleh Menteri Kesehatan, pelayanan kefarmasian harus dilakukan oleh apoteker dan TTK. Tenaga teknis kefarmasian yang melakukan pelayanan kefarmasian harus di bawah supervisi apoteker (Peraturan Menteri Kesehatan Republik Indonesia, 2016).

Rumah Sakit Amira Purwakarta merupakan rumah sakit umum swasta dengan kelas C. Dari hasil telaah dokumen resep selama satu tahun terakhir ini (JanuariDesember 2017) jumlah resep yang dilayani IFRS Amira Purwakarta menunjukkan peningkatan yang cukup tinggi, sekitar 30\%. Meningkatnya pelayanan resep tanpa diimbangi dengan penambahan jumlah tenaga dapat memberikan dampak pada meningkatnya beban kerja.

Berdasarkan hasil penelitian (Verawaty, 2016) di RS GPI Depok menyatakan bahwa peningkatan jumlah resep menyebabkan waktu tunggu pelayanan resep pasien menjadi lebih panjang dan memberi dampak beban kerja yang semakin tinggi (Verawaty, 2016). Personel IFRS Amira Purwakarta juga mengalami tekanan terhadap tumpukan resep yang menyebabkan bertambahnya jam kerja atau lembur. Tanda-tanda kelelahan dan kurangnya konsentrasi dalam bekerja dibuktikan dengan kejadian medication error selama enam bulan terakhir terjadi rata-rata 2 kejadian setiap bulannya yang bersifat error no harm berkaitan dengan wrong patient. Berdasarkan hasil penelitian (Donsu, 2016) di RSUP Prof. Dr. R.D. Kandau Manado bahwa faktor penyebab medical error pada fase dispensing diantaranya adalah beban kerja yaitu rasio 
antara beban kerja dan SDM tidak seimbang (Donsu, 2016). Penelitian Steyfan (Benawan, Citraningtyas, \& Wiyono, 2019) di RS Tobelo bahwa beban kerja yang tinggi salah satu faktor terjadinya medication error (Benawan et al., 2019).

Untuk pelayanan farmasi klinis di rawat jalan IFRS di RS Amira sudah melakukan PIO (Pelayanan Informasi Obat) untuk setiap obat yang akan diberikan pada pasien dan telah melakukan pengkajian resep berupa persyaratan adiministrasi, farmasetika dan klinis. Hal tersebut masih kurang harus adanya farmasi klinis di rawat inap berupa Rekonsiliasi Obat, Konseling, Visite, Pemantauan Terapi Obat (PTO), Monitoring Efek Samping Obat (MESO), Evaluasi Penggunaan Obat (EPO), Dispensing Sediaan Steril, dan Pemantauan Kadar Obat dalam Darah (PKOD). (Peraturan Menteri Kesehatan Republik Indonesia, 2016).

Kecukupan SDM di rumah sakit diatur pula oleh Permenkes No.56 Tahun 2014 di sesuaikan dengan kelas rumah sakit. Untuk rumah sakit umum kelas C, kategori/jenis pekerjaan dan rasio tenaga farmasi yang dibutuhkan untuk setiap unit pelayanan farmasi paling sedikit berjumlah delapan apoteker, satu orang apoteker sebagai kepala IFRS, dua apoteker yang bertugas di rawat jalan yang dibantu oleh paling sedikit empat orang TTK, empat orang apoteker di rawat inap yang dibantu oleh paling sedikit delapan orang TTK, satu orang apoteker sebagai koordinator penerimaan, distribusi dan produksi yang dapat merangkap melakukan pelayanan farmasi klinik di rawat inap atau rawat jalan dan dibantu oleh TTK yang jumlahnya disesuaikan dengan beban kerja pelayanan kefarmasian Rumah Sakit (Depkes, 2014). Kemudian pada Permenkes No.72 Tahun 2016 ditetapkan pula kebutuhan apoteker dihitung berdasarkan beban kerja, baik di unit pelayanan rawat jalan (satu tenaga apoteker untuk setiap 50 pasien) maupun, untuk unit rawat inap (satu apoteker untuk setiap 30 pasien) guna menjamin pemberian pelayanan kefarmasian yang layak (Peraturan Menteri Kesehatan Republik Indonesia, 2016).

Berdasarkan Keputusan Menteri Kesehatan Nomor 33tahun 2015 tentang Pedoman Penyusunan Perencanaan Sumber Daya Manusia Kesehatan jumlah SDM yang dibutuhkan sebuah rumah sakit dapat dihitung dengan menggunakan WISN (Worklood Indicators of Staffing Needs) berdasarkan indikator beban pekerjaan nyata yang dilakukan oleh tiap katagori SDM kesehatan pada tiap unit kerja fasilitas pelayanan kesehatan (Indonesia, 2019). Metode ini digunakan pula oleh WHO, dan dalam User's Manual WISN dijelaskan bahwa tujuan menejemen SDM adalah untuk memiliki SDM dengan jumlah yang tepat, waktu yang tepat, dan mengerjakan pekerjaan yang tepat sehingga pasien mendapat pelayanan yang layak dan, karenanya, terpuaskan (Organization, 2010).

Berdasarkan penelitian (Press \& Fullam, 2011) kepuasan pasien semakin diakui sebagai kunci ukuran kinerja suatu rumah sakit (Press \& Fullam, 2011). Kepuasan pasien sebagai pelanggan rumah sakit dapat diukur menggunakan metode Service Quality (Serqual). Untuk menganalisis berbagai atribut penting yang menjadi indikator tingkat kepuasan pasien tersebut, dapat digunakan metode Quality Function Deployment (QFD). Hasil analisis tersebut dapat menjadi masukan yang berharga bagi 
rumah sakit untuk menentukan kebijakan dalam meningkatkan kualitas pelayanan kefarmasian.

Berdasarkan latar belakang diatas, penulis ingin melakukan penelitian mengenai analisis kebutuhan sumber daya manusia dan kualitas pelayanan farmasi di RS Amira Purwakarta dengan tujuan untuk membantu perencanaan kebutuhan SDM yang sesuai dengan beban kerja rill dan upaya-upaya untuk memperbaiki pelayanan kefarmasian.

\section{Metode Penelitian}

Penelitian ini menggunakan pendekatan cross sectional, berupa penelitian deskriptif kuantitatif dengan menggunakan metode observasi, wawancara dan telaah dokumen (Sugiyono, 2017). Perhitungan beban kerja dilakukan dengan metode WISN. Penelitian ini dilakukan di Rumah Sakit Amira Purwakarta pada periode bulan April Mei 2018. Subjek penelitian adalah karyawan dan pasien atau keluarganya yang mengambil obat di pelayanan farmasi di RSU Amira Purwakarta yang memenuhi syarat inklusi sebanyak 6000 pasien, sehingga jumlah sampel yang dibutuhkan sebanyak 375 orang pasien. Sedangkan untuk sampel karyawan diambil seluruhnya dari populasi yang berkerja di IFRS Amira Purwakarta yaitu : apoteker, tenaga teknis kefarmasian dan tenaga administrasi yang bertugas di IFRS Amira Purwakarta. Analisis deskriptifini dilakukan untuk mengambil data tentang karakteristik tenaga kerja di IFRS Amira Purwakarta berupa: umur, jenis kelamin dan berapa jumlah tenaga kerja pada setiap jenis pekerjaan. Analisis kuantitatif digunakan untuk menghitung jumlah kebutuhan tenaga kerja. Dalam penelitian ini menggunakan metode WISN (Worklood Indicators of Staffing Needs).

\section{Hasil dan Pembahasan}

1. Analisis Deskriptif

Tabel 1

Karakteristik Tenaga kerja IFRS Amira Purwakarta

\begin{tabular}{|c|c|c|c|c|c|c|c|c|}
\hline $\begin{array}{c}\text { Umur } \\
\text { (Tahun) }\end{array}$ & $\mathbf{F}$ & $\%$ & $\begin{array}{c}\text { Jenis } \\
\text { Kelamin }\end{array}$ & $\mathbf{F}$ & $\%$ & Jenis Pekerjaan & $\mathbf{F}$ & $\%$ \\
\hline$<26$ & 16 & $76,191 \%$ & Laki-laki & 5 & $23,809 \%$ & Apoteker & 3 & $14,286 \%$ \\
\hline \multirow[t]{2}{*}{$26-36$} & \multirow[t]{2}{*}{4} & \multirow[t]{2}{*}{$19,047 \%$} & \multirow[t]{2}{*}{ Perempuan } & \multirow[t]{2}{*}{16} & \multirow[t]{2}{*}{$76,191 \%$} & TTK pelayanan & 11 & \multirow[t]{2}{*}{$57,143 \%$} \\
\hline & & & & & & TTK gudang & 1 & \\
\hline \multirow[t]{2}{*}{$>36$} & \multirow[t]{2}{*}{1} & \multirow[t]{2}{*}{$4,762 \%$} & & & & $\begin{array}{l}\text { Pengadministrasi } \\
\text { pelayanan }\end{array}$ & 5 & \multirow[t]{2}{*}{$28,571 \%$} \\
\hline & & & & & & $\begin{array}{l}\text { Pengadministrasi } \\
\text { gudang dan } \\
\text { purchasing }\end{array}$ & 1 & \\
\hline Jumlah & 21 & $100 \%$ & Jumlah & 21 & $100 \%$ & Jumlah & 21 & $100 \%$ \\
\hline
\end{tabular}

Sumber: pengolahan data primer 
Berdasarkan tabel 1 tentang karakteristik tenaga kerja IFRS dapat diketahui bahwa tenaga kerja paling banyak berumur kurang dari 25 tahun yaitu 16 orang (76,190\%), umur 26-36 tahun sebanyak 4 orang $(19,048 \%)$ dan paling sedikit adalah lebih dari 36 tahun sebanyak 1 orang $(4,762 \%)$. Menurut jenis kelamin paling banyak adalah perempun sebanyak 16 orang $(76,19 \%)$ dan laki-laki sebanyak 5 orang (3,809\%). Dari hasil tersebut kita dapat mengetahui perbandingan tenaga kerja perempuan dan laki-laki adalah 3:1. Menurut jenis pekerjaan diketahui bahwa, tenega kerja terbanyak di instalasi farmasi adalah tenaga teknis kefarmasian 12 orang $(57,143 \%)$, pengadministrasi 6 orang $(28,571 \%)$ dan paling sedikit apoteker 3 orang $(14,285 \%)$.

2. Analisis Kuantitatif

Analisis kuantitatif digunakan untuk menghitung jumlah kebutuhan tenaga kerja dengan metode WISN (Worklood Indicators of Staffing Needs), dengan langkah-langkah sebagai berikut:

a. Menetapkan Waktu Kerja Tersedia

Dengan peraturan di RS Amira Purwakarta untuk instalasi farmasi, dalam satu hari waktu kerjanya adalah 3 shift, waktu kerja untuk masing-masing shift adalah 8 jam/ hari. Berdasarkan data tersebut, maka dengan rumus Waktu Kerja Tersedia $=\{(\mathrm{A}-(\mathrm{B}+\mathrm{C}+\mathrm{D}+\mathrm{E})\} \times \mathrm{F}$, diperoleh waktu kerja tersedia ada di instalasi farmasi selama satu tahun adalah 2136 jam/tahun atau 128160 menit/tahun.

b. Menetapkan Unit Kerja dan Katagori SDM

Tabel 2

Unit Kerja dan Kategori SDM IFRS Amira Purwakarta

\begin{tabular}{|c|c|c|}
\hline Unit Kerja & Sub. Unit Kerja & Kategori SDM \\
\hline \multirow[t]{3}{*}{$\begin{array}{l}\text { Instalasi } \\
\text { Farmasi }\end{array}$} & $\begin{array}{l}\text { Instalasi Farmasi } \\
\text { Rawat Inap }\end{array}$ & $\begin{array}{l}\text { Apoteker, TTK (Tenaga teknis kefarmasian), } \\
\text { dan Pengaadministrasi }\end{array}$ \\
\hline & $\begin{array}{l}\text { Instalasi Farmasi } \\
\text { Rawat Jalan }\end{array}$ & $\begin{array}{l}\text { Apoteker, TTK (Tenaga teknis kefarmasian) } \\
\text { dan Pengaadministrasi }\end{array}$ \\
\hline & Gudang Farmasi & $\begin{array}{l}\text { Apoteker, TTK (Tenaga teknis kefarmasian) } \\
\text { dan Pengaadministrasi }\end{array}$ \\
\hline
\end{tabular}

Sumber: profil IFRS. Amira Purwakarta

Tabel 2. dapat diketahui bahwa SDM IFRS Amira Purwakarta untuk instalasi rawat inap dan instalasi rawat jalan dan gudang farmasi adalah apoteker, TTK dan pengadministrasi.

c. Menyusun Standar Beban Kerja

Secara garis besar menyusun stndar beban kerja dengan mengurai kegiatan-kegiatan pokok yang dilaksanakan oleh masing-masing sub unit kerja di IFRS Amira Purwakarta, selanjutnya menghitung rata-rata waktu yang diperlukan oleh masing-masing SDM dalam melaksanakan tiap-tiap kegiatan pokok. Terakhir diperoleh hasil perhitungan standar beben kerja tiap kegiatan pokok yang didapat pada hasil pembagian antara waktu kerja tersedia dengan rata-rata waktu pelaksanaan kegiatan pokok. 
d. Menyusun Standar Kelonggaran

Tabel 3

Standar Kelonggaran Tenaga IFRS Amira Purwakarta

\begin{tabular}{|c|c|c|c|c|}
\hline Kategori SDM & $\begin{array}{c}\text { Faktor } \\
\text { Kelonggaran }\end{array}$ & $\begin{array}{c}\text { Rata-rata } \\
\text { waktu } \\
\text { (jam/tahun) }\end{array}$ & $\begin{array}{c}\text { Waktu } \\
\text { kerja } \\
\text { tersedia }\end{array}$ & $\begin{array}{c}\text { Standar } \\
\text { kelonggaran }\end{array}$ \\
\hline 1 & 2 & 3 & 4 & 5 \\
\hline \multirow[t]{6}{*}{ Apoteker } & Rapat ruangan & 54 & 128160 & 0,025 \\
\hline & Seminar & 64 & 128160 & 0,030 \\
\hline & Rapat IAI & 24 & 128160 & 0,011 \\
\hline & Pelatihan & 126 & 128160 & 0,059 \\
\hline & Laporan RKO & 20 & 128160 & 0,009 \\
\hline & $\begin{array}{l}\text { Laporan SIPNAP } \\
\text { Sistem Pelaporan } \\
\text { Narkotika dan } \\
\text { Psikotropika }\end{array}$ & 36 & 128160 & 0,017 \\
\hline \multirow{4}{*}{$\begin{array}{ll}\text { Tenega } & \text { Teknis } \\
\text { Kefarmasian } & \text { (TTK) } \\
\text { dan } & \\
\text { Pengadministrasi }\end{array}$} & Rapat Ruangan & 18 & 128160 & 0,008 \\
\hline & Seminar & 48 & 128160 & 0,022 \\
\hline & Rapat PAFI & 15 & 128160 & 0,007 \\
\hline & Pelatihan & 90 & 128160 & 0,042 \\
\hline & Jumlah & & & $\mathbf{0 , 2 3 1}$ \\
\hline
\end{tabular}

Sumber: pengolahan data primer

Berdasarkan hasil pada tabel 3. standar kelonggaran untuk kategori apoteker, TTK, dan pengadministrasi tenaga kerja di IFRS Amira Purwakarta dari Tabel diatas sebesar 0,231

e. Menghitung kebutuhan tenaga Per Unit Kerja

Berdasarkan hasil analisis kuantitatif yang telah dilakukan untuk menghitung kebutuhan tenega kerja di IFRS Amira Purwakarta pada bulan April-Mei 2018 dengan metode WISN, didapat hasil berdasarkan penetapan unit kerja dan kategori SDM di IFRS dengan kualifikasi SDM di IFRS Amira Purwakarta yaitu: untuk pekerjaan kefarmasian terdiri dari Apoteker dan TTK. (Tenaga Teknis Kefarmasian) dan untuk penunjang terdapat Pengadministrasi. Sedangkan dalam Permenkes No. 72 Tentang Standar Pelayanan Kefarmasian di Rumah Sakit tahun 2016 yaitu: pekerjaan kefarmasian terdiri dari Apoteker dan TTK. (Tenaga Teknis Kefarmasian) penunjang terdiri dari operator computer /Teknisi yang memahami kefarmasian, Tenaga Administrasi dan Pekarya/Pembantu pelaksana (Peraturan Menteri Kesehatan Republik Indonesia, 2016).

Menghitung kebutuhan SDM di IFRS dengan cara data masing-masing kuantitas pokok yang telah didapatkan membaginya dengan masing-masing data standar beban kerjanya. Jumlah dari perhitungan tersebut adalah 24,240. Kemudian hasil tersebut ditambahkan dengan standar kelonggaran yaitu 24,240 $+0,231=24,471$. Jadi dari hasil yang diketahui bahwa jumlah SDM yang dibutuhkan berdasarkan beban kerja yang ditanggung oleh tenaga kerja di IFRS adalah sebanyak 25 orang. Untuk jumlah tenaga kerja tersedia di IFRS sebanyak 
21 orang, sehingga masih dibutuhkan tenaga kerja tambahan sebanyak 4 orang untuk menunjang pelayanan kefarmasian sesuai beban kerja. Tenaga kerja di IFRS terdiri dari tiga orang apoteker, satu apoteker sebagai kepala IFRS merangkap sebagai penyediaan sediaan farmasi dibantu satu orang TTK gudang dan satu orang Pengadministrasi gudang merangkap Purchasing, satu orang Apoteker bertugas di rawat jalan dibantu Sembilan orang TTK dan tiga orang Pengadministrasi, dan satu orang Apoteker bertugas dirawat inap dibantu dua orang TTK dan dua orang pengadministrasi.

Berdasarkan Permenkes No.56 Tahun 2014. Untuk rumah sakit umum kelas C, kategori/jenis pekerjaan dan rasio tenaga farmasi yang dibutuhkan untuk setiap unit pelayanan farmasi berjumlah delapan orang apoteker, satu orang apoteker sebagai kepala IFRS, dua apoteker yang bertugas di rawat jalan yang dibantu oleh paling sedikit empat orang TTK, empat orang apoteker di rawat inap yang dibantu oleh paling sedikit delapan orang TTK, satu orang apoteker sebagai koordinator penerimaan, distribusi dan produksi yang dapat merangkap melakukan pelayanan farmasi klinik di rawat inap atau rawat jalan dan dibantu oleh TTK yang jumlahnya disesuaikan dengan beban kerja pelayanan kefarmasian Rumah Sakit (Verawaty, 2016). Kemudian pada Permenkes No.72 Tahun 2016 ditetapkan pula kebutuhan apoteker dihitung berdasarkan beban kerja, baik di unit pelayanan rawat jalan (satu tenaga apoteker untuk setiap 50 pasien) maupun, untuk unit rawat inap (satu apoteker untuk setiap 30 pasien) guna menjamin pemberian pelayanan kefarmasian yang layak (Peraturan Menteri Kesehatan Republik Indonesia, 2016).

Untuk mengetahui menambahkan tenaga kerja sesuai dengan jam kerja sibuk, sehingga dicari distribusi beban kerja puncak di IFRS Amira Purwakarta, dengan cara dilakukan telaah dokumen berupa data waktu penyerahan resep dan waktu penyerahan obat yang terdapat di resep, sehingga bisa didapatkan waktu tunggu pelayanan resep di IFRS Amira Purwakarta. Dari hasil telaah dokumen yang dilakukan, IFRS Amira Purwakarta belum membagi pelayanan resep obat jadi dan racikan, sehingga pelayanan resep dikerjakan tidak ada perbedaan standar pelayanan untuk waktu tunggu obat jadi dan racikan. Untuk lama waktu tunggu di IFRS Amira Purwakarta pada jam sibuk waktu tunggu pelayanan resep bisa mencapai lebih dari 60 menit. Berdasarkan Keputusan Menteri Kesehatan RI Nomer: 129/Menkes/SK/II/2008 Tentang Standar Pelayanan Minimal Rumah Sakit, waktu tunggu pelayanan obat jadi $\leq 30$ menit dan racikan $\leq 60$ menit (Depkes, 2008).

Distribusi beban kerja puncak dapat diketahui dengan cara menghitung rata-rata waktu tunggu pelayanan resep pada saat ada praktek poliklinik. Diketahui di IFRS terbagi menjadi 3 shift, dimana pada shift pagi dan siang saja terdapat praktek poliklinik. Pada shift pagi jam 07:00-09:00 mempunyai rata-rata waktu tunggu pelayanan resep (18,07 menit), jam 09:00-11:00 (21,8 menit), jam 11:00-13:00 (37,3 menit), dan jam 13:00-15:00 (35, 25 menit). Kemudian di 
shift siang 15:00-17:00 mempunyai rata-rata waktu tunggu pelyanan resep (41,4 menit), jam 17:00-19:00 (67,25 menit), dan pada jam 19:00-21:00 (54 menit). Hasil ini menunjukkan bahwa pada shift pagi mengalami jam sibuk mulai dari jam 11 dengan rata-rata waktu tunggu pelayanan resep > 30 menit, dan pada shift siang jam sibuk sudah terjadi pada awal jam masuk kerja dengan beban kerja punyak pada jam 17:00-19:00 dengan waktu > 60 menit.

Salah satu metode pengumpulan data yang dilakukan dalam penelitian ini adalah wawancara. Wawancara ini merupakan metode pengumpulan data secara langsung untuk mendapatkan keterangan secara lisan dari seseorang yang menjadi sasaran penelitian atau responden penelitian. Wawancara dalam penelitian ini dilakukan kepada 20 orang tenaga kerja yang ada di IFRS untuk mewakili 21 orang jumlah keseluruhan tenaga kerja yang ada. Hasil wawancara diperoleh data dari aspek pekerjaan yang membutuhkan waktu terbanyak adalah pelayanan resep dengan jawaban dari 16 orang (80 \%). Pekerjaan yang dilakukan oleh tenaga kerja jika tidak sedang melayani pasien adalah melaksanakan pekerjaan administrasi yang dijawab oleh semua responden (20 orang atau 100\%). Untuk penggunaan waktu kerja "sibuk" pernyataan ini berdasarkan hasil jawaban 12 orang tenaga kerja (60\%). Jawaban pertanyaan mengenai jumlah tenaga kerja, sebagian besar tenaga kerja di IFRS yang diwawancarai "kurang" jawaban 14 orang tenaga kerja (80\%) dan menurut mereka membutuhkan tambahan tenaga kerja kira-kira sebanyak 1-4 orang lagi (80\%), karena menurut mereka penambahan SDM akan mengurangi beban kerja sehingga pelayanan akan berjalan lebih cepat.

Berdasarkan hasil yang telah diketahui dari penelitian kebutuhan SDM sesuai beban kerja di IFRS menunjukkan kekurangan jumlah tenaga kerja sebanyak 4 orang. Hasil perhitungan 4 orang tersebut dapat ditentukan jenis pekerjaannya yaitu TTK sebanyak 3 orang dibagi atas shift pagi ditambah 1 orang dengan jam masuk middle yaitu dari jam 11:00-18:00 dan 2 orang masuk pada shift siang, dan pengadministrasi sebanyak 1 orang pada shift malam ini didasari pada hasil wawancara tenaga kerja di IFRS dimana shift malam mempunyai beban kerja yang berat karena terdapat pelayanan pasien IGD dan pelayanan resep rawat inap dimalam hari, serta pengadministrasian resep sisa shift siang.

Berdasarkan keputusan Mentri Kesehatan RI Nomor 81/MENKES/SK/2004, menyebutkan bahwa rata-rata waktu yang dibutuhkan untuk menyelesaikan suatu kegiatan bervariasi dan dipengaruhi oleh standar pelayanan. Standar Oprasional Prosedur (SOP), sarana dan prasarana yang tersedia serta kompetensi SDM (Posuma, 2013).

Berdasarkan hasil penelitian yang telah dilakukan IFRS Amira Purwakarta setelah menambah jumlah SDM sesuai dengan beban kerja, diharapkan akan memperbaiki kualitas pelayanan kefarmasian, tetapi untuk kesesuaian dengan peraturan perundang-undangan masih dibutuhkan tenaga kerja lebih banyak lagi 
karena masih ada pelayanan kefarmasian yang belum dijalankan. Pelayanan farmasi klinik yang sudah ada adalah pengkajian dan pelayanan resep, dan Pelayanan Informasi Obat (PIO) untuk dirawat jalan. Sementara itu pelayanan farmasi klinik dirawat inap yang lainnya belum berjalan. Menurut Permenkes Nomer 72 Tentang Standar Pelayanan Kefarmasian di Rumah Sakit. Pelayanan farmasi klinik yang dilakukan meliputi Pengkajian dan Pelayanan Resep, Penelusuran Riwayat Penggunaan Obat, Rekonsiliasi Obat, Pelayanan Informasi Obat (PIO), Konseling, Visite, Pemantauan Terapi Obat (PTO), Monitoring Efek Samping Obat (MESO), Evaluasi Penggunaan Obat (EPO), Dispensing Sediaan Steril, dan Pemantauan Kadar Obat dalam Darah (PKOD) (Peraturan Menteri Kesehatan Republik Indonesia, 2016).

Kemudian untuk memenuhi standar pelayanan kafarmasian tidak lepas dari persyaratan Akreditasi Rumah Sakit. Standar Nasional Rumah Sakit (SNARS) yang telah ditetapkan oleh Komisi Akreditasi Rumah Sakit (KARS) berlaku mulai tanggal 1 januari 2018. Instrument SNARS Edisi 1 yang terdapat dalam pelayanan kefarmasian adalah standar Pelayanan Kefarmasian dan Penggunaan Obat (PKPO). Elemen penilaiannya antara lain pembentukan Komite Farmasi dan Terapi (KFT), penyusunan formularium rumah sakit yang merupakan tugas KFT, dan elemen farmasi non klinik dan farmasi klinik.

Kemudian standar lain yang harus dipenuhi IFRS terkait akreditasi adalah Sasaran Keselamatan Pasien (SKP), Asesmen Pasien (AS), Menejemen Komunikasi dan Edukasi (MKE), Peningkatan Mutu dan Keselamatan Pasien (PMKP), Pencegahan dan Pengendalian Infeksi (PPI), Menejemen Informasi dan Rekam Medis (MIRM), dan Program Nasional.

\section{Analisis upaya peningkatan mutu pelayanan IFRS}

1. Penyusunan Kuesioner

Pernyataan dalam kuesioner yang terdiri dari lima dimensi. Kelima dimensi tersebut adalah tangible, reliability, responsiveness, assurance, dan emphaty (Putra, 2014). Dimensi tersebut dikembangkan menjadi 22 atribut yang menjadi pertanyaan didalam kuesioner dan menjelaskan apa saja yang harus dipenuhi oleh IFRS Amira Purwakarta untuk memenuhi kebutuhan pasien yang ada akhirnya akan memuaskan pasien IFRS Amira Purwakarta.

2. Perhitungan Service Quality

Digunakan metode SerQual karena metode tersebut mempunyai validasi dan reabilitas yang baik dan juga diterapkan secara luas untuk penilaian kepuasan pasien. ${ }^{18}$ Penilaian kepuasan pasien dilakukan oleh 375 pasien rawat jalan yang sedang menunnggu pelayanan IFRS Amira Purwakarta. Skor SerQual didapat dengan cara menghitung berdasarkan rumus:

\section{Skor Serqual $=$ Skor Persepsi - Ekspektasi}

Jika hasil yang diperoleh positif, berarti pelayanan yang diberikan pihak IFRS melebihi harapan pasien. Jika hasil yang diperoleh adalah nol, berarti pelayanan yang diberikan pihak IFRS sesuai dengan yang diharapkan oleh 
pasien. Jika hasil yang diperoleh pelayanan yang diberikan pihak IFRS adalah negatif, berarti pelayanan yang diberikan pihak IFRS belum sesuai dengan harapan pasien atau dengan kata lain pihak IFRS belum dapat memuaskan pasien.

Tingkat kepuasan pasien dapat diketahui dengan menggunakan metode SerQual yaitu gap 5 yang berarti terdapat gap antara pelayanan yang dirasakan dengan pelayanan yang diharapkan oleh pasien. Penilaian kepuasan dilakukan oleh 375 pasien rawat jalan yang sedang menunggu pelayanan IFRS. Hasil perhitungan dari Skor SerQual menunjukkan hasil gap untuk tiap dimensi. Gap terbesar pada dimensi responsiveness (-0,581), diikuti dimensi Assurance 0,511) dan Tangible (-0,507). Dapat dikatakan pasien merasa ada atribut pernyataan yang belum memenuhi harapan pasien dengan pelayanan IFRS Amira Purwakarta terutama pada dimensi responsiveness.

Deskripsi kepuasan pasien rawat jalan berdasarkan penilaian harapan dan persepsi mengenai pelayanan di IFRS Amira Purwakarta dapat dilihat pada gambar 1.

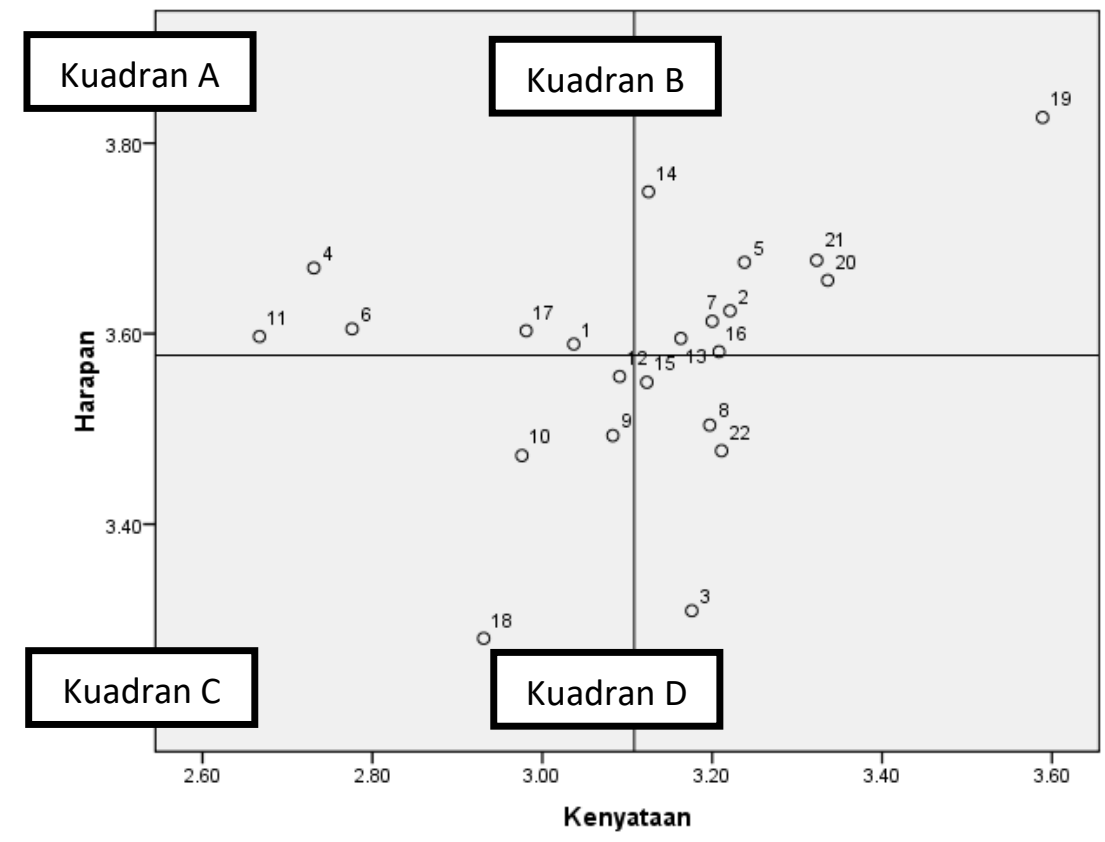

\section{Gambar 1 \\ Diagram Kartesius 22 Atribut Pernyataan Kuesioner IFRS Amira Purwakarta}

Keterangan:

Kuadran A: Prioritas utama/ konsentrasi (atribut 1, 4, 6, 11, 17)

Kuadran B: Prestasi yang baik (pertahankan) (atribut 2,5,7,13,16, 20, 21)

Kuadran C: Prioritas rendah (atribut 9, 10, 12, 18)

Kuadran D: Berlebihan (atribut 3, 8, 15, 22)

Sumber: Data Primer 
Hasil penelitian dengan kartesius adalah dengan melihat atribut apa saja yang termasuk dalam kuadran A, B, C dan D.

a. Atribut-atribut yang termasuk dalam kuadran A (Prioritas Utama), menunjukkan atribut-atribut yang mempengaruhi kepuasan konsumen, namun pihak IFRS belum mampu melaksanakannya dengan baik, meliputi: atribut 1 (RS. Amira Purwakarta memiliki instalasi farmasi peralatan yang lengkap), atribut 4 (Obat di Instalasi Farmasi lengkap sesuai yang dibutuhkan pasien), atribut 6 (Instalasi Farmasi menyediakan petugas yang lebih pada saat jam-jam sibuk), atribut 11 (Pelayanan di Instalasi Farmasi cepat) dan atribut 17 (Karyawan Instalasi Farmasi bekerja masih tanpa salah). Atribut 6, 11, 17 saling berhubungan, jika IFRS menambah petugas pada jam-jam sibuk maka pelayanan dapat dilakukan lebih cepat. Untuk atribut 1 dan 4 IFRS bisa mengatasinya dengan melakukan penambahan dan pembenahan fasilitas teknis dan mengatasi masalah pengadaan obat di IFRS.

b. Atribut-atribut yang termasuk dalam kuadran B (Prestasi yang baik), menunjukkan atribut yang mempengaruhi kepuasan konsumen antara lain: atribut 2 (RS. Amira Purwakarta memiliki ruang tunggu gedung instalasi farmasi yang aman), atribut 5 (Karyawan Instalasi Farmasi selalu memberikan pelayanan yang baik), atribut 7 (Kemampuan karyawan Instalasi Farmasi dapat dipercaya), atribut 13 (Karyawan Instalasi Farmasi bersedia membantu dalam menyesuaikan masalah obat yang dialami pasien), atribut 16 (Karyawan Instalasi Farmasi bersikap sopan \& ramah terhadap pasien), atribut 20 (Instalasi farmasi memiliki karyawan yang dapat membantu pasien menangani masalah obatnya) dan atribut 21 (Karyawan Instalasi Farmasi memperhatikan kebutuhan obat yang digunakan pasien). Ini menunjukkan bahwa pasien menginginkan pelayanan yang cepat dan informasi obat yang dapat dipercaya sesuai dengan harapan pasien.

c. Atribut-atribut yang termasuk dalam kuadran C (prioritas rendah) menunjukkan bahwa atribut yang berada pada kuadran ini dianggap penting oleh konsumen, sedangkan kualitas pelayanan yang diberikan IFRS tergolong cukup antara lain : atribut 9 (Karyawan Instalasi Farmasi mempunyai catatan pengobatan pasien), atribut 10 (Karyawan Instalasi Farmasi memberitahu kapan obat akan diberikan), atribut 12 (Karyawan Instalasi Farmasi selalu bersedia untuk membantu pasien). Atribut 18 (Karyawan Instaalasi Farmasi memberikan perhatian individual kepada pasien)

d. Atribut-atribut yang termasuk kuadran D menunjukkan bahwa atribut yang berada pada kuadran ini dianggap kurang penting oleh konsumen antara lain: atribut 3 (Karyawan Instalaasi Farmasi Penampilannya menarik), atribut 8 (Karyawan Instalasi Farmasi memberikan penjelasan mengenai obat dengan jelas dan mudah dimengerti), atribut 15 (Pasien merasa aman dan yakin dalam membeli obat di Instalasi Farmasi), atribut 22 (Karyawan Instalasi 
Farmasi memahami kebutuhan pasien (mudah berkomunikasi dengan pasien))

Oleh karena itu, langkah yang perlu dilakukan selanjutnya adalah mengidentifikasi hal-hal apa saja yang dianggap penting bagi pasien dan upaya apa saja yang dapat dilakukan oleh IFRS Amira Purwakarta sehingga pasien dapat merasa puas dengan pelayanan IFRS Amira Purwakarta. Untuk mengetahui hal tersebut digunakan metode QFD.

3. Aplikasi Quality Function Deployment (QFD)

Dalam pengaplikasian QFD terdapat House of Quality merupakan bagian dari proses QFD yang menggunakan sebuah matriks pernyataan untuk menghubungkan keinginan pelanggan (pasien rawat jalan) dengan upaya perusahaan (pihak IFRS) melakukan sesuatu untuk memenuhi keinginan tersebut. Pembuatan HOQ dilakukan dalam beberapa tahapan dan berikut merupakan tahapan pembuatan HOQ (Yanti S, 2014).

\section{a. Identifikasi Customer Requirement}

Pada tahap ini, customer requirement atau biasa disebut dengan voice of customers didapat dari pengembangan lima dimensi SerQual. Kelima dimensi tersebut menjadi primary requirement, sedangkan pengembangan dari lima dimensi yang berupa 22 atribut pertanyaan menjadi secondary requirement. Secondary requirements akan menjadi voice of customers dan terletak pada dinding sebelah kiri dalam penyusunan HOQ alasan mengapa ke 22 atribut dapat menjadi voice of coustomer adalah karena metode serqual bukanlah jawaban akhir dalam menilai dan meningkatkan kualitas pelayanan, tetapi merupakan awal titik untuk melakukan langkah selanjutnya (Donsu, 2016).

\section{b. Penilaian Kinerja Pelayanan IFRS. Amira Purwakarta}

Penilaian kinerja pelayanan IFRS. Amira Purwakarta dilakukan mengetahui seberapa besar kinerja yang telah dilakukan oleh IFRS. Penilaian dilakukan oleh pasien, penilaian tersebut didasarkan pada pelayanan yang dirasakan oleh pasien. Data pelayanan kinerja didapatkan dari kuesioner kenyataan, menggunakan sekala likert 1 sampai dengan 4 kinerja akan dikatakan bagus jika mendapatkan nilai 4. Penilaian dilakukan dengan cara menterjemahkan seluruh nilai kenyataan yang diberikan responden pada tiap-tiap atribut, kemudian dibagi dengan jumlah responden.

Berdasarkan hasil perhitungan diketahui bahwa menurut pasien kinerja IFRS. Amira Purwakarta secara umum dapat dikatakan baik karena memiliki rata-rata kinerja sebesar 3,108. Kinerja terbaik IFRS Amira Purwakarta pada atribut 19 (Instalasi Farmasi beroprasi 24 jam) dengan nilai 3,589, atribut 20 (Instalasi farmasi memiliki karyawan yang dapat membantu pasien menangani masalah obatnya) dengan nilai 3,336 dan atribut 21 (Karyawan Instalasi Farmasi memperhatikan kebutuhan obat yang digunakan pasien) 3,323. Sementara kinerja terburuk menurut pasien adalah atribut 11 
(Pelayanan di Instalasi Farmasi cepat) dengan nilai 2,667, atribut 4 (Obat di Instalasi Farmasi lengkap sesuai yang dibutuhkan pasien) dengan nilai 2,731 dan atribut 6 (Instalasi Farmasi menyediakan petugas yang lebih pada saat jam-jam sibut) dengan nilai 2,776. IFRS Amira Purwakarta perlu mempertahankan kinerja yang telah dianggap baik oleh konsumen dan juga perlu memperhatikan atribut yang dirasakan pasien mempunyai kinerja yang buruk supaya pelayanan yang diberikan sesuai dengan harapan pasien.

\section{c. Menentukan Tingkat Kepentingan}

Tahapan ini bertujuan untuk mengetahui seberapa penting tiap atribut menurut persepsi pasien sehingga diharapkan dapat memuaskan pasien. Data kepentingan di dapat dari data kuesioner kepentingan. Nilai kepentingan tiap atribut dihitung dengan cara menjumlahkan seluruh nilai kepentingan yang diberikan responden. Semakin besar nilai rata-rata tiap atribut maka semakin penting atribut tersebut untuk dipenuhi oleh pihak IFRS Amira Purwakarta.

Berdasarkan hasil perhitungan diperoleh bahwa atribut-atribut yang dianggap penting oleh pasien yaitu peringkat pertama pada atribut 4 (Obat di Instalasi Farmasi lengkap sesuai yang dibutuhkan pasien) dengan nilai 3,765 dan atribut 19 (Instalasi Farmasi beroprasi 24 jam) dengan nilai 3,765, peringkat ke dua atribut 14 (Karyawan Instalasi Farmasi memiliki pengetahuan yang memadai untuk menjawab pertanyaan pasien) dengan nilai 3,733 dan peringkat ke tiga atribut 5 (Karyawan Instalasi Farmasi selalu memberikan pelayanan yang baik) dengan nilai 3,725. Atribut-atribut yang dianggap paling penting oleh pasien perlu mendapatkan perhatian lebih dari pihak IFRS Amira Purwakarta.

\section{d. Menentukan Goal dan Improvement Ratio}

Goal merupakan suatu target yang perlu dicapai oleh IFRS. Amira Purwakarta untuk memenuhi coustomer requirements yang ditentukan oleh kepala IFRS yang dinyatakan dengan skala likert yaitu antara 1 untuk sangat tidak baik sampai dengan 4 untuk sangat baik. Improvement ratio merupakan tahap dimana IFRS. Amira Purwakarta dapat mengetahui seberapa besar perbaikan yang harus dilakukan.

Pada goal kepala IFRS tidak diberikan nilai maksimal kepada setiap atribut kerena kepala IFRS Amira purwakarta mempertimbangkan sumber daya yang dimiliki. Semakin tinggi nilai goal yang diteteapkan oleh kepala IFRS maka Improvement Ratio juga bias semakin tinggi apalagi kalua nilai atributnya mempunyai nilai kinerja yang rendah. Dengan diketahuinya nilai Improvement Ratio maka kepala IFRS mendapatkan informasi mengenai kondisi kinerja IFRS Amira Purwakarta saat ini terhadap target yang ditetapkan yang sesuai dengan kemampuan IFRS Amira Purwakarta. Semakin tinggi nilai Improvement Ratio maka menandakan kenyataan yang masih kurang baik dan membutuhkan perbaikan secepatnya. Berdasarkan hasil perhitungan Improvement Ratio terdapat satu atribut yang memiliki 
nilai paling tinggi yaitu atribut 11 (Pelayanan di Instalasi Farmasi cepat) dengan nilai 1,500. Hal ini menunjukkan bahwa IFRS. Amira Purwakarta harus secepatnya melakukan perbaikan atau evaluasi agar hal yang serupa tidak terjadi kembali.

\section{e. Menentukan Design Requirement}

Tahap selanjutnya dalam pembuatan HOQ adalah menerjemahkan customer requiremen dengan menyesuaikan kondisi yang ada sehingga dapat dilaksanakan oleh pihak IFRS Amira Purwakarta. Dengan kata lain design requiremant merupakan hal-hal teknis untuk memenuhi keinginan pasien. Untuk menentukan desigen requirement dilakukan wawancara dengan kepala IFRS. Design Requirement yang didapat dari hasil wawancara dengan kepala instalasi sebagai berikut:

1) Pembenahan dan penambahan fasilitas fisik seperti penambahan kursi pasien, microphone yang memadai, meja compounding dan membenahi layout. Untuk meningkatkan kenyamanan pasien menunggu obat dan mempercepat pelayanan.

2) Perluasan tempat instalasi farmasi dan sistem distribusi desentralisasi berupa pendistribusian persediaan perbekalan farmasi yang mempunyai cabang di dekat unit pelayanan.

3) Komputerisasi label obat untuk menghindari kesalahan proses dispensing obat.

4) Evaluasi SOP untuk memperbaiki proses pelayanan.

5) Evaluasi penerapan formularium untuk memudahkan perencanaan dan penyediaan obat.

6) Pengaturan jadwal dokter untuk menghindari banyaknya pasien di jam yang bersamaan.

7) Pelatihan pengadaan obat untuk dapat melakukan pengadaan dengan lebih sesuai kebutuhan dan pengadaan obat secara katalog elektronik.

8) Pertemuan rutin dengan progremer. Pertemuan untuk mengontrol penggunaan SIM (sistem informasi manajemen) rumah sakit dan mengevalusinya sehingga ada perbaikan dalam program yang digunakan.

9) Pelatihan teknis dilakukan untuk meningkatkan pengetahuan dan keterampilan farmasi berupa pelatihan pelayanan, seminar dan workshop.

\section{f. Analisis Keeratan Hubungan antara Atribut Customer Requirement dengan Design Requirement}

Tahap selanjutnya menganalisis hubungan antara customer requirement dan design requirement. Hal ini bertujuan mengetahui keeratan hubungan antara requirement dengan design requirement. Dalam menunjukkan hubungan keduanya digunakan symbol $\bullet$ mempunyai bobot 9 yang artinya terdapat hubungan yang kuat, simbol mempunyai bobot nilai 3 yang artinya terdapat hubungan yang sedang dan symbol mempunyai bobot 1 yang artinya terdapat hubungan yang lemah. Tingkat 
keeratan hubungan antara customer requirement dengan design requirement diketahuai dengan melakukan wawancara dengan kepala IFRS Hasil analisis keeratan hubungan akan menentukan tingkat kepentingan tiap atribut design Requirement yang akan berpengaruh pada prioritas tindakan yang akan dilakukan.

\section{g. Menentukan Hubungan antara Design Requirement}

Untuk menentukan hubungan antar design requiremen dilakukan wawancara dengan kepala IFRS Amira Purwakarta dalam menentukan hubungan digunakan simbol, symbol + apabila hubungan antara design requiremen saling mendukung dan simbol $\mathrm{x}$ apabila hubungan antara design requiremen saling melemah.

Berdasarkan hasil wawancara dengan kepala IFRS Amira Purwakarta, tidak terdapat hubungan saling melemah antar design requirement. Hubungan antar design requirement yang saling mendukung yaitu:

1) Penembahan dan penambahan fasilitas fisik dengan Perluasan tempat instalasi farmasi dan system distribusi desentralisasi serta Komputerisasi label obat.

2) Perluasan tempat instalasi farmasi dan system distribusi desentralisasi dengan Komputerisasi label obat.

3) Komputerisasi label obat dengan Evaluasi SOP dan Pertemuan rutin dengan progremer.

4) Evaluasi penerapan formularium dengan Evaluasi penerapan formularium.

5) Pelatihan pengadaan obat dengan Pelatihan teknis.

\section{h. Menentukan Tingkat Kepentingan Tiap Atribut Design Requiremen}

Tahap akhir dalam pembuatan HOQ adalah menentukan tingkat kepentingan tiap Design Requiremen. Tahap ini menentukan manakah Design Requirement yang paling penting atau diprioritaskan untuk segera ditindak lanjuti. Terdapat dua kepentingan yaitu kepentingan absolute dan kepentingan relative.

Nilai kepentingan absolute didapat dengan menjumlahkan symbolsimbol dalam hubungan antara customer requirement dengan design requiremen pada tiap design requiremen yang sebelumnya telah dikalikan dengan nilai kepentingan pasien. Setelah itu jumlahkan kepentingan absolute untuk menghitung kepentingan relative. Kepentingan relative dapat dihitung dengan cara membagi kepentingan absolute dengan jumlah kepentingan absolute dikalikan $100 \%$. Langkah selanjutnya adalah membuat peringkat dari kepentingan relative, nilai yang paling penting menjadi peringkat pertama. 
Tabel 4

Tingkat Kepentingan Design Requirement

\begin{tabular}{llccc}
\hline No & \multicolumn{1}{c}{ Design Requirement } & $\begin{array}{c}\text { Kepentingan } \\
\text { Absolut }\end{array}$ & $\begin{array}{c}\text { Kepentingan } \\
\text { Relatif }\end{array}$ & Peringkat \\
\hline 1 & $\begin{array}{l}\text { Pembenahan dan penambahan } \\
\text { fasilitas fisik }\end{array}$ & 146.248 & 16,559 & 2 \\
\hline 2 & $\begin{array}{l}\text { Perluasan tempat instalasi farmasi } \\
\text { dan system distribusi desentralisasi }\end{array}$ & 114.460 & 12,959 & 3 \\
\hline 3 & Komputerisasi label obat & 68.579 & 7,765 & 8 \\
\hline 4 & Evaluasi SOP & 96.924 & 10,974 & 4 \\
\hline 5 & Evaluasi penerapan formularium & 87.774 & 9,938 & 5 \\
\hline 6 & Pengaturan jadwal dokter & 74.847 & 8,474 & 7 \\
\hline 7 & Pelatihan pengadaan obat & 47.931 & 5,427 & 9 \\
\hline 8 & Pertemuan rutin dengan progremer & 84.286 & 9,543 & 6 \\
\hline 9 & Pelatihan teknis & 162.168 & 18,361 & 1 \\
\hline & Jumlah & $\mathbf{8 8 3 . 2 1 7}$ & $\mathbf{1 0 0 \%}$ & \\
\hline
\end{tabular}

Sumber: Pengolahan Data Primer

Berdasarkan perhitungan tersebut dapat dilihat tiga peringkat tertinggi dari design requirement yaitu pelatihan teknis, penambahan dan pembenahan fasilitas fisik serta perluasan ruang dan instalasi desentralisasi. Diharapkan dengan diketahuinya tiga peringkat tertinggi dari design requirement dapat menjadi masukan bagi pihak IFRS Amira Purwakarta dan pihak menejen RS Amira Purwakarta.

Berdasarkan uraian diatas, tindakan yang dapat disarankan kepada pihak IFRS serta kepada pihak menejemen RS Amira Purwakarta adalah:

1) Pelatihan teknis diharapkan akan bisa mengatasi masalah dan memberikan informasi obat kepada pasien dengan baik, serta meningkatkan kesigapan dalam bekerja.

2) Pembenahan dan penambahan fasilitas fisik untuk membuat pasien lebih nyaman dalam menunggu obat, menghindari kesalahan pemberian obat dan mempercepat proses dispensing resep.

3) Perluasan tempat instalasi farmasi dan system distribusi desentralisasi untuk menghindari penumpukan pasien disatu tempat dan membuat pelayanan fermasi lebih terjangkau oleh pasien atau tenaga kesehatan lain sehingga pelayanan bisa lebih cepat.

4) Evaluasi SOP dan Evaluasi Penerapan Formularium sebisa mungkin diperbaiki, walaupun ini bukan peringkat teratas dalam prioritas tetapi dapat memberikan peningkatan kepuasan pelayanan dan evaluasi penerapan formularium akan meningkatkan kepatuhan dokter akan formularium sehingga mengurangi masalah ketersediaan obat.

\section{i. House of Quality (HOQ)}

Setelah semua analisis dilakukan maka HOQ pun dapat dibuat. HOQ merupakan gabungan semua analisis, dari analisis SerQual hingga 
perhitungan kepentingan relative. Secara lengkap HOQ dapat dilihat pada gambar. Keterangan gambar:

1) Customer requirement: merupakan input dalam HOQ yang berasal dari pengembangan kuesioner serqual.

2) Design requirement: merupakan penerjemahan dari Customer requirement oleh pihak IFRS Amira Purwakarta untuk memenuhi keinginan pasien.

3) Tingkat kepentingan: diperoleh dari penilaian responden terhadap atribut dalam Customer requirement.

4) Harapan: merupakan penilaian responden terhadap pelayanan IFRS Amira Purwakarta yang mereka harapkan.

5) Kinerja: merupakan penilaian dari responden mengenai pelayanan IFRS Amira Purwakarta yang mereka rasakan.

6) Skor serqual: merupakan besarnya selisih antara harapan dengan kinerja (kenyataan).

7) Goal: merupakan target yang ingin dicapai oleh IFRS Amira Purwakarta untuk memenuhi Customer requirement.

8) Improvement ratio: dihitung dengan membagi goal dengan kinerja sehingga didapat diketahui seberapa besar perbaikan yang perlu dilakukan.

9) Kepentingan absolut: menunjukkan design requirement yang perlu diprioritaskan untuk dilakukan terlebih dahulu.

\section{Kesimpulan}

Analisis kesenjangan (gap) digunkan terbukti kualitas pelayanan kefarmasian di IFRS Amira Purwakarta masih ada kekurangan, ditunjukkan dengan masih kurangnya SDM sebanyak 4 orang yang dilihat dari analisis beban kerja (WISN) dan untuk penentuan jenis pekerjaan yang perlu penambahan SDM diketahui dengan melihat nilai distribusi beban kerja puncak dan dilakukan wawancara pada tenaga kerja di IFRS sehingga didapat 3 orang TTK dan 1 pengadministrasi. Dengan menambah jumlah SDM sesuai dengan beban kerja, diharapkan kualitas pelayanan kefarmasian dapat diperbaiki, tetapi untuk kesesuaian dengan peraturan perundang-undangan masih ada kurang tenaga kerja karena masih banyak pelayanan yang belum dijalankan pelayanan farmasi klinik misalnya, hanya terdapat pelayanan pengkajian dan pelayanan resep, dan Pelayanan Informasi Obat (PIO). Kemudian, untuk memenuhi standar pelayanan kafarmasian, tidak lepas dari persyaratan Akreditasi Rumah Sakit yang harus dipenuhi. Untuk masukan dari Kepala IFRS yang merupakan jawaban dari suara kunsumen/pasien (QFD) dalam upaya meningkatkan kualitas pelayanan kefarmasian yaitu pelatihan teknis kepada karyawan, pembenahan dan penambahan fasilitas fisik, perluasan tempat instalasi farmasi dan sistem distribusi desentralisasi, dan Evaluasi SOP dan Evaluasi Penerapan Formularium. 
Agan syahrial, Shirly Kumala, Prih Sarnianto, Yetty Hersunaryati

\section{BIBLIOGRAFI}

Benawan, Steyfan, Citraningtyas, Gayatri, \& Wiyono, Weny I. (2019). Faktor Penyebab Medication Error Pada Pelayanan Kefarmasian Rawat Inap Bangsal Anak RSUD Tobelo. Pharmacon, 8(1), 159-167. Google Scholar

Depkes, R. I. (2008). Standar Pelayanan Minimal Rumah Sakit. Jakarta: Departemen Kesehatan RI, 18. Google Scholar

Depkes, R. I. (2014). Peraturan Menteri Kesehatan Republik Indonesia Nomor 56 Tahun 2014 tentang Klasifikasi dan Perijinan Rumah Sakit. Jakarta: Departemen Kesehatan RI.

Donsu, Yosefien Ch. (2016). Faktor Penyebab Medication Error pada Pelayanan Kefarmasian Rawat Inap Bangsal Anak RSUP Prof. Dr. RD Kandou Manado. PHARMACON, 5(3). Google Scholar

Indonesia, Kemenkes Republik. (2019). Peraturan Menteri Kesehatan Republik Indonesia Nomor 33 Tahun 2015 Tentang Pedoman Penyusunan Perencanaan Kebutuhan Sumber Daya Manusia. Google Scholar

Organization, World Health. (2010). Workload indicators of staffing need. Google Scholar

Peraturan Menteri Kesehatan Republik Indoonesia. (2016). Nomor 72 Tentang Standar Pelayanan Kefarmasian di Rumah Sakit. 42.

Posuma, Christilia O. (2013). Kompetensi, kompensasi, dan kepemimpinan pengaruhnya terhadap kinerja karyawan pada Rumah Sakit Ratumbuysang Manado. Jurnal EMBA: Jurnal Riset Ekonomi, Manajemen, Bisnis Dan Akuntansi, 1(4). Google Scholar

Press, Irwin, \& Fullam, Francis. (2011). Patient satisfaction in pay for performance programs. Quality Management in Healthcare, 20(2), 110-115. Google Scholar

Putra, Wahyu Manggala. (2014). Analisis Implementasi Kebijakan Jaminan Kesehatan Nasional di Rumah Sakit Umum Kota Tangerang Selatan Tahun 2014. Google Scholar

Sembiring, Jimmy Joses, \& SH, M. (2010). Smart hrd: Perusahaan tenang, karyawan senang. VisiMedia. Google Scholar

Sugiyono. (2017). Metode Penelitian Pendidikan (Pendekatan Kuantitatif, Kualitatif, dan $R \& D)$. Bandung: Alfabeta. Google Scholar

Verawaty. (2016). Analisis Kebutuhan Tenaga Kefarmasian di Instalasi Farmasi Rumah Sakit Graha Permata Ibu Tahun 2016. Magister Ilmu Farmasi, Universitas Pancasila Jakarta Selatan, 7(2), 65-74. 
Analisis Kebutuhan Sumber Daya Manusia dan Kualitas Pelayanan Farmasi Di RS Amira Purwakarta

Yanti S. (2014). Analisis Kebutuhan Sumber Daya Manusia Instalasi Farmasi Rumah Sakit Hana Chritas Bengkulu Utara. Tesis. Sumedang: Universitas Padjajaran, 1415 .

\section{Copyright holder:}

Agan syahrial, Shirly Kumala, Prih Sarnianto, Yetty Hersunaryati (2022)

First publication right:

Syntax Literate: Jurnal Ilmiah Indonesia

\section{This article is licensed under:}

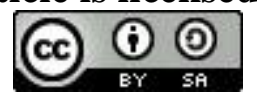

